\title{
Deterioration of dolostone by magnesium sulphate salt: an example of incompatible building materials at Bonaval Monastery, Spain
}

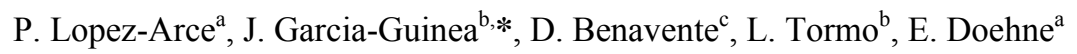 \\ ${ }^{a}$ Getty Conservation Inst., 1200 Getty Center Drive, Suite 700, Los Angeles, CA 90049, USA \\ ${ }^{\mathrm{b}}$ Museo Nacional de Ciencias Naturales (CSIC). 28006, Madrid, Spain. \\ ${ }^{\mathrm{c}}$ Laboratorio de Petrologia Aplicada, Unidad Asociada CSIC-UA. Departamento de CC. de la Tierra \\ y del Medio Ambiente-Universidad de Alicante. 03080, Alicante, Spain \\ *Corresponding author. Tel.: +34-91-4111-328; fax.: +34-91-5644740. \\ E-mail address: guinea@mncn.csic.es (J. Garcia-Guinea).
}

\begin{abstract}
Since its abandonment 185 years ago, the XII century Santa Maria de Bonaval Monastery located in Guadalajara (Spain) has suffered significant deterioration: first the roof was lost, followed by partial collapse of the walls, moisture infiltration and extensive loss of stone surfaces due to salt weathering. This case study is a clear example of the incompatibility of some building materials: in this case, the combination of sulphate-bearing mortars and magnesium-rich stone and mortars leading to extensive weathering by magnesium sulphate crystallization. Samples of plaster, bedding and core mortars, stone fragments and flakes, salt crust and powders were collected, as well stone samples from the historic quarries located close to the Monastery. Characterization by XRD (X-ray diffraction), ESEM-EDS (environmental scanning electron microscopy with energy dispersive X-ray spectroscopy) shows that the most important stone-type used in the structure, dolostone, is mainly affected by magnesium sulphate salts (epsomite, $\left.\mathrm{MgSO}_{4} \cdot 7 \mathrm{H}_{2} \mathrm{O}\right)$, although other salts as kalicinite $\left(\mathrm{KHCO}_{3}\right)$ and mercallite $\left(\mathrm{KHSO}_{4}\right)$ were also detected. The connected porosity and pore size distribution determined by mercury intrusion porosimetry and capillarity behaviour suggest that the core mortar could easily be dissolved and the stone, plaster and bedding mortars are able to transport infiltrating solutions, giving rise to the precipitation of magnesium sulphate in the mortar joints and over the surface of the stone. Due to their chemical incompatibility, the combination of sulphate and magnesium-bearing mortars and stone with high magnesium content appears to be problematic and should be avoided in future restoration work. Keywords: Stone deterioration; Dolostone; Flaking; Salt decay; Magnesium sulphate; Epsomite
\end{abstract}




\section{Introduction}

The Medieval ruins of the Santa Maria de Bonaval Monastery (1164 AD) are located in Tamajon, in the state of Guadalajara (Spain), a region where the geology consists largely of dolomitic limestone from the Cretaceous period and the climate has a continental character with an average temperature of $5 \mathrm{C}^{\mathrm{o}}$ and relative humidity of $78 \%$ in winter and $25 \mathrm{C}^{\circ}$ and $40 \%$ in summer.

In the XVIII century, the monastery was partially restored, but in 1821 the Cistercian Monks left the Monastery for Toledo. It should be stressed that one of the main problems at the monastery is the too long lack of maintenance, until partial collapse. Today, although the church, the headwall, a vestry, the crosspiece and the meridian bay retain their original structure, the monastery is in a poor state of conservation. It displays areas of structural failure and walls extensively affected by magnesium sulphate salts associated with flaking and fracturing of the dolomitic stone in the interior walls. Also, alveolar weathering is found in stones on the exterior East and West walls, displaying powdering of the bricks located in the frames of the windows from the North and West walls of the building.

Magnesium sulphate is considered a very destructive salt that plays an important role in the deterioration of stone [1-3]. The original source of magnesium present in magnesium sulphate efflorescence is generally tied to be the composition of the building materials used for construction, mainly dolomite or magnesium limestone [1,4-6] as well as magnesium-rich mortars [2,7-10]. Mortars can also be a source of sulphates [6], however, pollution-related, atmospheric $\mathrm{SO}_{2}$ is also a very common source of sulphates $[11,12]$.

The main objectives of this work are to provide a case study of stone deterioration in a historic building due to the action of salts originating largely from the building materials themselves, and to attempt to understand the causes and mechanisms of decay, so that others may avoid the use of incompatible buildings materials in future restoration works.

\section{Materials and Methods}

\subsection{Geological setting}

The ruins of the Monastery are located at the riverbank junction of Jarama and Retiendas rivers, which supply enough water to keep the Monastery foundations wet and result in rising damp in the walls up to 2 meters high (Fig. 1). Cistercian monks selected this isolated valley (Fig. 1a) because of the water, the flat land and probably because they found a complete set of building materials close at hand: (i) quartz sand 
and slate pebbles from rivers and riverbanks, (ii) dolomitic stone in the Pila hill for blocks and to obtain lime-mortars, perhaps with the assistance of a hydraulic sawmill situated close to the Monastery in the boundary of the riverbank with the Cretaceous dolomite hill of Pila, (iii) plastic clays from the neighbouring Tertiary Pliocene Raña to manufacture local fired bricks and some adobe blocks, (iv) gypsum from the Tertiary Oligocene for plasters and wall coverings. It is interesting to note that all of these building materials can be collected from the area surrounding of the Monastery not more than one or two kilometres away.

\subsection{Building materials}

The outcrops of stone which appear to have supplied the quarry stone to build the Monastery were located and 4 samples collected: sample C1 and sample C2 from outcrops facing North, and sample C3 and sample C4 from outcrops facing West (Fig. 1b).

An interior and an exterior area of the Monastery were selected to collect samples (Fig. 2a and 2b). The interior East wall of the structure located under the dome is built with regular blocks of stone as two vertical masonry layers, like a double wall. In the interior of this wall there is a core mortar that is filling the double wall. The blocks of stone are jointed from each other by a bedding mortar. Finally, the external surface of the wall is covered by a thin layer mortar or plaster mortar (Fig. 2c). In this wall were collected 3 samples of mortars: sample B1 (plaster mortar), sample B2 (bedding mortar) and sample B3 (core mortar); 3 samples of salts (Fig. 2d): sample B5 (salt powder under a scale), sample B6 (efflorescence of salt crust) and sample B7 (efflorescence of salt powder in joints); and 2 samples of stone: sample B8 (stone flake) and sample B9 (stone fragment). In the exterior East wall of the building, 1 sample of stone flake was collected (sample B4).

\subsection{Analytical techniques and experimental procedures}

To determine the mineralogical composition of salts, mortars and stone samples, analyses by X-ray diffraction (XRD) were carried out using a Phillips PW-1710 powder diffractometer with CuKa radiation. Patterns were obtained by step scanning from $3^{\circ}$ to $75^{\circ} 2 \theta$ with a count for $0.5 \mathrm{~s}$ per step, exploration speed of $7^{\circ}$ minute ${ }^{-1}$ and $40 \mathrm{kV}$ and $40 \mathrm{~mA}$ in the X-ray tube.

The chemical composition of samples was performed by X-Ray Fluorescence (XRF) using a PHILIPS PW-1404 with an Sc-Mo tube, using Ge, LIF220, LIF200, PE and TLAP as analyser crystals and a SuperMananager-Q software from Panalytical-Spain in the Museo Nacional Ciencias Naturales of Madrid (Spain) using pellets of $8 \mathrm{~g}$ of milled sample pressed under $20 \mathrm{TM}$ and dried at $40{ }^{\circ} \mathrm{C}$. 
Thin-section examination of the stones was carried out using Polarizing Light Microscopy (PLM) with a Nikon Eclipse (C POL 600) microscope, equipped with an automatic photographic system and a digital camera (Model Nikon Coolpix 950).

The salt samples were also studied with the environmental scanning electron microscopy (ESEM) using a Quanta 200 FEI microscope with energy dispersive X-ray spectroscopy (EDS) (model 7509 Oxford Instrument Analytical, UK). Furthermore, some ESEM experiments were performed with the Peltier stage changing the temperature and relative humidity to observe how the magnesium sulphate salt crystallizes and dissolves inside the pores and over the surface of some stone samples.

To assess the pore structure of stone and mortars, connected porosity (P) and pore size distribution (PSD) were determined by mercury intrusion porosimetry (MIP) in a radius range of $0.003-200 \mu \mathrm{m}$ (by Autopore IV 9500 Micromeritics).

The capillary imbibition test was carried out using a continuous data-recording. The balance device was linked to a computer which automatically records weight gain in the tested specimen at specified intervals (every 10 seconds in the current study). It allows automatic monitoring of the water uptake by the sample when its lower surface is in contact with the water reservoir. The continuous absorption method permits an extremely accurate characterisation of building materials with high absorption rates $\left(\mathrm{C}>10 \mathrm{Kg} / \mathrm{m}^{2} \mathrm{~h}^{0.5}\right)$ and also with narrow contact area, in comparison with the non-continuous standard method [13].

Five specimens of slate have been tested for Magnesium leaching by immersion of cut slabs with dimensions $2 \times 3 \times 0.4 \mathrm{~cm}^{3}$ in a sulphuric acid solution, for 1 week with solution concentrations of $10 \%$ (sample S10), 20\% (sample S20), 40\% (sample S40), 80\% (sample S80) and 100\% (sample S100), to study the possible contribution of the slate aggregates from the bedding mortar as a source of magnesium and potassium for the formation of sulphates containing these cations.

\section{Results and discussion}

\subsection{Field overview}

From field observations in winter, can be noted that the stone from the monument displays several types of weathering laminations parallel to the surface of the walls, showing scaling $(<1 \mathrm{~mm}$ of thickness), flaking (1-10 mm of thickness) and fracturing (1-5cm of thickness). In the exterior walls, there is also alveolar deterioration of the stone and powdering of bricks. Salts are present as white powder 
efflorescences in the bedding mortar joints (between the blocks of stone) in the interior and exterior walls and as crusts covering the surface of the stones in the interior walls. Another visit to the monastery during the summer season showed efflorescences crusts covering the surface of the stone also in the exterior walls, suggesting some change in salt distribution over seasons.

\section{2. $X$-Ray diffraction (XRD)}

The results obtained from the analyses of the samples by XRD (Table 1) show that the stone fragments (sample B9) and the stone flakes (samples B4 and B8) are dolomite $\mathrm{MgCa}(\mathrm{CO} 3)_{2}$, while the powder founded under the flakes (sample B5) is magnesium sulphate salt (epsomite, $\mathrm{MgSO}_{4} \cdot 7 \mathrm{H}_{2} \mathrm{O}$ ) and dolomite. The analyses of the salt crust, collected on January, at the beginning of winter, over the surface of the stone (sample B6) and the white powder in the bedding mortar joints (sample B7) is also epsomite in both cases. XRD analyses of salt efflorescences from the same areas, carried out on samples collected six months later, on September, at the end of the summer, shown hexahydrite $\left(\mathrm{MgSO}_{4} \cdot 6 \mathrm{H}_{2} \mathrm{O}\right)$ instead of epsomite. This would confirm a seasonal change on the hydration state of this salt, leading to its dehydration, after summer, and its hydration, after the autumn and beginning of winter.

The mortars were also analysed, showing a bulk composition for the plaster mortar (sample B1) of 76\% of calcite $\left(\mathrm{CaCO}_{3}\right), 9 \%$ of gypsum $\left(\mathrm{CaSO}_{4} \cdot 2 \mathrm{H}_{2} \mathrm{O}\right)$ and $11 \%$ of magnesite $\left(\mathrm{MgCO}_{3}\right)$. The bedding mortar (sample B2) is $9 \%$ calcite binder with aggregates of $56 \%$ quartz $\left(\mathrm{SiO}_{2}\right), 4 \%$ of albite feldspar $\left(\mathrm{NaAlSi}_{3} \mathrm{O}_{8}\right)$ and slate $\left(20 \%\right.$ of illite $\left(\mathrm{K}, \mathrm{H}_{3} \mathrm{O}\right)(\mathrm{Al}, \mathrm{Mg}, \mathrm{Fe})_{2}(\mathrm{Si}, \mathrm{Al})_{4} \mathrm{O}_{10}\left[(\mathrm{OH})_{2}\left(\mathrm{H}_{2} \mathrm{O}\right)\right], 10 \%$ muscovite $\left(\mathrm{KAl}_{2}\left(\mathrm{Si}_{3} \mathrm{Al}\right) \mathrm{O}_{10}(\mathrm{OH}, \mathrm{F})_{2}\right.$ and $10 \%$ of chlinoclore $\left.\left(\mathrm{Mg}, \mathrm{Fe}^{2+}\right)_{5} \mathrm{Al}\left(\mathrm{Si}_{3} \mathrm{Al}\right) \mathrm{O}_{10}(\mathrm{OH})_{8}\right)$. The white core mortar used in the interior of the walls (sample B3) is $14 \%$ quartz and $5 \%$ illite as aggregates, and $81 \%$ of calcium sulphates, as $58 \%$ gypsum and $23 \%$ bassanite $\left(\mathrm{CaSO}_{4} \cdot 1 / 2 \mathrm{H}_{2} \mathrm{O}\right)$ as binder, suggesting that core mortar and the plaster mortar are the source of the sulphate for the precipitation of magnesium sulphate salt. The origin of magnesium could be related with the composition of the dolomitic stone $\mathrm{CaMg}\left(\mathrm{CO}_{3}\right)_{2}$, but also to the mortars, since these have magnesite (sample B1) and slate aggregates (samples B2 and B3) with high magnesium content.

Mortars made by mixing lime and gypsum have been used very often during the XVII, XVIII, XIX centuries, for wall and joints restorations and as stuccos or plasters over the stone surface, and occasionally were also made of pure gypsum [14]. The binder fraction of ancient mortar samples from five Italian Churches from Northern Italy was analysed by Bruni S. et al. [15] and they found three different species of lime composed of: (i) calcareous lime with only calcite, in the bedding or jointing 
mortars (XV century) for brick masonry, (ii) magnesium lime with calcite and magnesite, in the painted plasters (XV century), and (iii) magnesium lime with calcite and magnesite and hydromagnesite in the exterior plasters covering the masonries (VI-VII, XVII and XV centuries). While they could be older, the plaster (with 11\% magnesite and 9\% gypsum) and the core mortars (with $81 \%$ calcium sulphate) used in the Bonaval monastery may also have been applied during restoration works carried out in the XVII century.

\subsection{X-Ray fluorescence (XRF)}

The XRF analyses (Table 2) are in accordance with the results obtained by XRD, but with XRF it is possible to distinguish exactly the percentages of $\mathrm{CaO}$ and $\mathrm{MgO}$ in all samples. These percentages are very similar in both, the stone samples from the building (samples B8 and B9), and those stones collected from the outcrops (samples $\mathrm{C} 3$ and $\mathrm{C} 4$ ), with $\sim 36 \%$ of $\mathrm{CaO}$, and $\sim 16 \%$ of $\mathrm{MgO}$ in the sample of dolomite from the quarry (sample $\mathrm{C} 3$ ), and $\sim 36 \%$ of $\mathrm{CaO}$, and $\sim 18 \%-19 \%$ of $\mathrm{MgO}$ in the samples from the monastery (samples B8 and B9), respectively. The percentage of $\mathrm{MgO}$ is slightly higher ( $2 \%-3 \%)$ in the samples from the building, but this could be due to the fact that in the building the samples are affected by the presence of magnesium sulphate. The samples of stone flakes (samples B8 and B4) and the salt crust (sample B6) display very similar amount of $\mathrm{MgO}(\sim 17 \%)$. Magnesium is also present in the plaster and bedding mortar (samples B1 and B2 with $\sim 15 \%$ and $\sim 7 \%$, respectively). The mortars samples also show the presence of potassium $\left(\mathrm{K}_{2} \mathrm{O}\right)$ with a similar percentage in the bedding mortar (sample $\mathrm{B} 2$ ) and the core mortar (sample B3) ( 2.3\%).

The sulphur concentration in the samples can be related with the sulphate content, which in the case of the magnesium sulphate salt crust (sample B6) is $281,324 \mathrm{ppm}$. This quantity is close to that obtained in the core mortar analysis $(268,561 \mathrm{ppm})$ that consists of gypsum and bassanite (calcium sulphates). In the other samples, the amount of sulphur is much lower; the plaster mortar contains $43,821 \mathrm{ppm}$. The samples of stone flakes (samples B4 and B8) display 9,710 ppm and 14,925 ppm, respectively. The stone fragment (sample B9) has 4,562 ppm, and the stones from the outcrops (samples C3 and C4) are below $1000 \mathrm{ppm}$, which means that the stones from the monastery are affected by an external source of sulphur. These results are consistent with the source of sulphates being from the mortars.

\subsection{Polarizing Light Microscopy (PLM)}

The sample B9 (identified as dolomite by XRD) displays many similarities with the stone collected from the West outcrop (sample C3) (identified also as dolomite by XRD) and, as was mentioned above, 
contains a similar percentage of $\mathrm{MgO}$. The thin sections of the samples have been dyed with alizarin red to distinguish the calcite from the dolomite (calcite stains pink). Some micro-fissures filled with calcite can being observed in both samples and also some orange areas stained by the presence of iron oxides (Fig. 3a). The thin sections of both samples under PLM also show the presence of some small calcite micro-nodules of $\cong 1 \mathrm{~mm}$ of diameter embedded in a calcareous micritic matrix with small aggregates of dolomite (Fig. 3b). The similar aspect and optical features in both samples, suggest that they may have the same origin. The stone from the building (sample B9) may have come from the West outcrop, where the sample $\mathrm{C} 3$ was collected.

\subsection{Environmental scanning electron microscopy with energy dispersive X-ray spectroscopy (ESEM-} EDS)

The samples of salt crust and powder (B6 and B7, respectively) under the ESEM show the presence of potassium salts, kalicinite $\left(\mathrm{KHCO}_{3}\right)$ and needle shape mercallite $\left(\mathrm{KHSO}_{4}\right)$ (Fig. 4a), together with a net of epsomite crystals (Fig. 4b), with signs of partial dissolution of dolomite (Fig. 4c). The salt under the stone scale (sample B5) is also epsomite, but contains loose dolomite crystals as well. Some needle shape epsomite crystals were also observed in the mouth of a pore from one of the stone flakes. This morphology can suggest slow rates of precipitation of epsomite, which can give rise to larger crystals precipitating in the pores.

To observe how the magnesium sulphate crystallizes and dissolves inside the pores of the stone samples, some ESEM experiments were performed controlling the temperature and relative humidity (RH) with a Peltier stage (Fig. 5). The first experiment was performed after submerging the flakes from sample B8 and a piece of stone from sample B9 in a magnesium sulphate solution during 24 hours at room temperature. The RH was decreased from $100 \%$ down to $65 \%$ to obtain a rapid crystallization of the epsomite at $16^{\circ} \mathrm{C}$, but the magnesium sulphate solution was still covering the surface of the flake sample B8 and no crystallization was observed (Fig. 5a). The RH was decreased to $10 \% \mathrm{RH}$ at $22^{\circ} \mathrm{C}$, but the magnesium sulphate was not observed to crystallize, neither in the pores nor in the surface (Fig. 5b), suggesting that it migrated through the pores to the bottom of the stone sample.

Another experiment in the ESEM involved the dissolution of an epsomite crystal at its equilibrium RH $\left(90 \%\right.$ at $20^{\circ} \mathrm{C}$ ). Lowering rapidly the RH to $65 \%$, the crystallization occurred as a crust with a ribbed texture over the surface of the Peltier stage. After cycling several times the temperature, between $40^{\circ} \mathrm{C}$ and $0^{\circ} \mathrm{C}$, and the $\mathrm{RH}$, between $70 \%$ and $0 \%$, a crack in the crust was produced when the $\mathrm{RH}$ was 
decreased below 55\% (Fig. 5c). This crust tended to be opened when the RH was decreased below 55\% and tended to be closed when the RH was increased above $55 \%$ until $90 \%$, the moment in which the crust started to dissolve because the deliquesce point for this salt was achieved. When decreasing again the RH, the crystallization started rapidly at $\sim 80 \% \mathrm{RH}$ as a crust with rugged edges. When lowering the $\mathrm{RH}$ to $55 \%$ a crack was formed again. The changes in temperature and relative humidity inside the ESEM chamber were applied in order to cross the phase transition boundary between epsomite and hexahydrite (Fig. 6). The same behaviour observed under the ESEM could be taking place in the epsomite crust over the surface of the stone in the Monastery. The cracking of the crust attached to the stone, could occur due to changes in temperature and humidity, playing an important role in the mechanism of flaking and decay of the stone, during seasonal weathering changes between hot and dry summers and cold and humid winters. However, looking at the phase diagram of magnesium sulphate for Temperature-Relative Humidity (Fig. 6), and taking into account the average atmospheric conditions where the Monastery is located $\left(\mathrm{T}=5^{\circ} \mathrm{C}\right.$ and $\mathrm{RH}=78 \%$ in winter and $\mathrm{T}=25^{\circ} \mathrm{C}$ and $\mathrm{RH}=40 \%$ in summer, it could be that the winter may be the more stable season. In summer, small diurnal changes in temperature and $\mathrm{RH}$ are enough to cross the limit of the phase transition between epsomite and hexahydrite, and hydration and dehydration of magnesium sulphate could easily occur.

\subsection{Experimental attack of slate with sulphuric acid}

In order to evaluate the contribution of the slate (from the aggregates of mortars) in the formation of salts, five specimens of slate were attacked with sulphuric acid solutions. The original composition of the slate was analysed by XRF (Table 3) where the percentage of $\mathrm{Fe}_{2} \mathrm{O}_{3}$ is $6.27 \%$ and $\mathrm{MgO}$ is $3.32 \%$ and by XRD displaying quartz, clinochlore ferroan $\left(\begin{array}{llllll}\mathrm{Mg}, & \mathrm{Fe})_{6} & (\mathrm{Si}, \mathrm{Al})_{4} & \mathrm{O}_{10}(\mathrm{OH})_{8} & \text { and } & \text { muscovite }\end{array}\right.$ $\left(\mathrm{KAl}_{2}\left(\mathrm{Si}_{3} \mathrm{Al}\right) \mathrm{O}_{10}(\mathrm{OH}, \mathrm{F})_{2}\right.$. The specimens attacked with a $10 \%$ and $20 \%$ solutions of sulphuric acid (samples S10 and S20), did no show signs of weathering. The specimens attacked with a 40\%, $80 \%$ and $100 \%$ concentration (samples S40, S80 and S100) displayed an efflorescence crust in the lateral sides of the slabs. The XRD analyses of the samples S40 and S80 display halotrichite $\left(\mathrm{FeAl}_{2}\left(\mathrm{SO}_{4}\right)_{4} \cdot 22 \mathrm{H}_{2} \mathrm{O}\right)$ and magnesium sulphate pentahydrite $\left(\mathrm{MgSO}_{4} \cdot 5 \mathrm{H}_{2} \mathrm{O}\right)$. The sample $\mathrm{S} 100$ displays mainly halotrichite, magnesium sulphate pentahydrite and iron oxide. Although mainly iron sulphates and no potassium salts were precipitated, this experiment does show that extreme weathering of the slate aggregates could contribute to the formation of magnesium sulphate salts.

3.7. Mercury intrusion porosimetry (MIP) 
The connected porosity (P) and pore size distribution (PSD) of the stone and mortar samples, determined by mercury intrusion porosimetry (MIP), is shown in Table 3 and Fig. 7.

The PSD of stone samples C3, B9 and B8 (Fig. 7a, 7b and 7c) are similar, with some slight differences suggesting the evolution of the pore system from the unaltered stone in the quarry (sample C3) and the stone in the building altered by the magnesium sulphate crystallization (sample B8 and B9). The pore size distribution of the stone from the quarry (sample C3, Fig. 7a) shows that the average pore radius ranges 0.1 to $0.6 \mu \mathrm{m}$, while for the stone fragment in the building (sample B9, Fig. $7 \mathrm{~b}$ ) it ranges from 0.5 to $2 \mu \mathrm{m}$ and in the stone flake (sample B8, Fig. $7 \mathrm{c}$ ) the average pore radius ranges 0.6 to $2 \mu \mathrm{m}$. Moreover, an increase of connected porosity in the weathered stones is also observed. There is an increase in the pores $>1 \mu \mathrm{m}$ and a decrease in those $<1 \mu \mathrm{m}$, in the weathered stone in the building compared to the unaltered stone in the quarry.

The evolution of the pore structure, in the weathered stone in the building compared to the unaltered stone in the quarry, can be interpreted as a combination of: (1) the mineral dissolution by meteoric waters; (2) salt weathering, which creates tensile stress over the pore surface and can produce microcracking by the extension and widening of existing microcracks and pores. These processes locally increase the pore radius and consequeltly, this may in turn facilitate the water transport throught stones. (3) Finally, some re-dissolution-precipitation processes may modify the PSD of the stones by the preferential dissolution of high surface area regions.

The PSD of the mortars (Fig. 7d, 7e and 7f) suggests that samples B1 and B2 have crystals with a homogeneous size, like a well-sorted stone. Thus, sample B3 it is more heterogeneous, since it has a polymodal distribution, meaning that the bigger pores are controlling the transport of fluids.

\subsection{Water absorption by capillarity}

The capillary imbibition kinetic of the three different mortars and stones from the building is represented in Fig. 8. The first part of each curve defines the capillary absorption and the second part defines the saturation. The slope of the curve during capillary absorption is the capillary absorption coefficient, C (Table 3). This coefficient, $\mathrm{C}$, is closely related to pore structure by the pore radius and the porosity. The $\mathrm{r}_{\mathrm{M}}$ (Table 3) and the connected porosity values are smaller in sample B1 than in sample B2, and that explains because the coefficient, $\mathrm{C}$, is higher in $\mathrm{B} 2$ compared to $\mathrm{B} 1$. The evolution of the porous media parameters is reflected in the increasing of water absorption coefficients of the weathered stones, and consequenly, in the permability. The capillary absorption coefficient is related to the square root of the 
permeability, $\mathrm{C} \propto \sqrt{\mathrm{k}}_{\mathrm{k}}[13,16]$. Thus, using different correlations between the capillary absorption coefficient and water permeability in porous stones [13], the variation of the square root of the permeability, $\Delta \mathrm{k}$, with the capillary coefficient, $\Delta \mathrm{C}$, may be estimated as: $\Delta \sqrt{ } \mathrm{k}(\mathrm{mD}) \sim 3 \Delta \mathrm{C}\left(\mathrm{kg} / \mathrm{m}^{2} \cdot \mathrm{h}^{0.5}\right)$. From this correlation, the increase of stone permeability by the weathering processes may be established in $\sim 780 \mathrm{mD}$ and $\sim 100 \mathrm{mD}$ for B8 and B9 samples respectively (1D is roughly $10^{-12} \mathrm{~m}^{2}$ or $10^{-5} \mathrm{~m} / \mathrm{s}$ for pure water at $\left.20^{\circ} \mathrm{C}\right)$.

The capillary absorption coefficient of the core mortar (sample B3) is very high $18.31 \mathrm{~kg} / \mathrm{m}^{2} \cdot \mathrm{h}^{0.5}$ (Table 3), suggesting rapid water transport which could easily dissolve calcium sulphate (gypsum and bassanite) and therefore, provide a source of $\mathrm{SO}_{4}{ }^{2-}$. The rapid infiltration of water through the pore structure of mortars may result in an undersaturated solution, with insufficient time to reach the equilibrium (saturation) with respect to the gypsum. This results in the solution being more able to dissolve material over some distance.

The capillary absorption coefficient of the bedding mortar (sample B2) and of stone from the building (sample B9) is much lower (4.23 and $5.13 \mathrm{~kg} / \mathrm{m}^{2} \cdot \mathrm{h}^{0.5}$, respectively) compared with the water absorption of the core mortar (sample B3). This means that the transport of moisture is slower, allowing the water concentrated in sulphates coming from the dissolution of the core mortar to combine with the magnesium from the dissolution of the stone and from the mortar aggregates. Ultimately, this gives rise to the precipitation of epsomite, both in the bedding mortar and in the stone.

\subsection{Final discussions}

In the Bonaval Monastery, magnesium sulphate was found to precipitate as efflorescence as a hard crust covering the stone surface and as a powder in the mortar joints between blocks of stone, and as cryptoefflorescence some millimetres under the surface of the stone (under the flakes).

From all the obtained results can be pointed out that the important sulphate sources for salt precipitation seems to be the calcium sulphate $(80 \%)$ core mortar used as filler between walls, but also the plaster mortar with a $9 \%$ of gypsum. It is known that the origin of magnesium can be related to the composition of the dolomite stone [17]. Caner E.N. et al. [4] found efflorescences of epsomite and hexahydrite continuously formed in the drying zones of the dolomitic stone in the Divrigi Great Mosque-Turkey. They observed powdering at the exposed surfaces and formation of cracks in the interiors of the exposed surfaces followed by the loss of hand-size or larger fragments (similar to sample B9). In their research the laboratory dissolution of dolomite shows the release of magnesium ions from the stone in alkaline 
medium with or without sulphate ions. The plaster and bedding mortar can not be disregarded as a source of magnesium, because the former is $\sim 15 \% \mathrm{MgO}$ (obtained by XRF) with a presence of $11 \%$ magnesite (MgCO3), while the latter is $7 \%$ of $\mathrm{MgO}$ from the presence of phyllosilicates (as illite and chlinoclore in the slate aggregates, detected by XRD) with magnesium in their composition. These aggregates of slate have been found in the monastery mixed with the epsomite powder efflorescence in the joints of the stone blocks, probably because they have been separated from the mortar due to the transport of water solutions. In part, the presence of magnesium sulphate (epsomite) and the potassium salts as well, kalicinite $\left(\mathrm{KHCO}_{3}\right)$ and mercallite $\left(\mathrm{KHSO}_{4}\right)$, can be explained by the salt solutions transport across the lime bedding mortar, which extracts the potassium and magnesium from the slate fragments embedded as aggregates in the core and bedding mortar (Fig. 9). Because of the high solubility of epsomite, efflorescences containing this salt are mainly found in places protected from the direct access of rain [2] sometimes penetrating to great depths into the stone before crystallizing [3]. Epsomite is a very soluble salt, frequently able to convert the ambient moisture into liquid water [18] and the presence of other salts in solution can modify its properties; e.g. its solubility is slightly increased with $\mathrm{K}_{2} \mathrm{SO}_{4}[19]$.

Laboratory experiments carried out in two types of magnesian limestone cubes impregnated with a salt mixture [20], have shown that a salt mixture with deliquescent salts of low equilibrium relative humidity (RHeq) produces earlier damage by flaking of stone by humidity fluctuations compared to a single salt (magnesium sulfate) that tends to form a crust with no damage observed in the stone. Although flaking or delamination of stone it is usually caused by crypto-efflorescence, the process of damage due to repeated cycles of dissolution and crystallization of the relatively soluble magnesium sulfate salts is due to the presence of liquid water or, more often, deliquescence at high humidity, and the fluctuations between high a low relative humidity.

A preliminary model can be presented in which the combination of moisture, soluble sulphate and soluble magnesium leads to cycles of salt crystallisation and flaking of stone over a time period of at least 150 years and possibly up to several hundred years.

\section{Conclusions}

The combination of sulphate-bearing mortars (gypsum and bassanite) and magnesium from the dolomite stone, magnesite of the plaster mortar and Mg-rich aggregate embedded in the bedding mortar appear to have resulted in extensive salt weathering in the Bonaval Monastery. 
Magnesium sulphate salt appear as crusts over the surfaces and under the flakes of the stone and as powder efflorescences on the mortar bedding joints between blocks of stone as minor amounts of kalicinite $\left(\mathrm{KHCO}_{3}\right)$ and mercallite $\left(\mathrm{KHSO}_{4}\right)$ and mainly epsomite $\left(\mathrm{MgSO} 4 \cdot 7 \mathrm{H}_{2} \mathrm{O}\right)$ at the beginning of winter and hexahydrite (MgSO4 $6 \mathrm{H}_{2} \mathrm{O}$ ) at the end of summer, confirming so, the seasonal change on the hydration state of this salt.

The capillary absorption coefficient of the core mortar is very high, suggesting rapid water transport which could easily dissolve calcium sulphate (gypsum and bassanite) and therefore, provide a source of $\mathrm{SO}_{4}{ }^{2-}$. The capillary absorption coefficient of the stone and bedding mortar is much lower, meaning that the transport of moisture is slower, allowing the water concentrated in sulphates coming from the dissolution of the core mortar to combine with the magnesium from the dissolution of the stone and from the mortar aggregates. Ultimately, this gives rise to the precipitation of epsomite, both in the bedding mortar and in the stone.

Due to their chemical incompatibility, the combination of sulphate and magnesium-bearing mortars and stone with high magnesium content should be avoided in future restoration works.

\section{Acknowledgements}

The authors thank to the Ministry of Science and Technology JCCM, Toledo (Spain) and the European Social Fund, for supporting the post-doctoral fellowship to develop this work. Thanks also to Giacomo Chiari, chief scientist of the Getty Conservation Institute (GCI), which it is the host institution for the post-doctoral fellow of Paula Lopez-Arce. We are also grateful to Martin Férnandez-Hernán for being always a source of ideas and an explorer, geologist and archaeologist. Finally thanks to the Spanish projects C.I.C.Y.T.-CGL2004-03564/BTE and MATERNAS-S-0505/MAT/000094 that supported the work.

\section{References}

[1] Schaffer RJ. The weathering of Natural Building Stones. London: HMSO, department of Scientific and Industrial Research Special Report, 1932.

[2] Charola AE, Lewin SZ. Efflorescences on building stones-SEM in the characterization and elucidation of mechanisms of formation. Scan Electron Micros 1979;1: 379-386.

[3] Cooke RU, Gibbs GB. Crumbling Heritage? Studies of stone weathering in polluted atmospheres. National Power plc and PowerGen plc, 1991. 
[4] Caner EN, Demirci S, Turkmenoglu AG. Deterioration of dolomite by soluble salts in Divrigi Mosque-Turkey. In: Felix G, editor. Proceedings of the Vth International Congress on deterioration and conservation of stone. Lausanne: 1985. vol.1, p.299-305.

[5] La Iglesia A, Garcia del Cura MA, Ordoñez S. The physicochemical weathering of monumental dolostones, granites and limestones; dimension stones of the Cathedral of Toledo (Spain). Sci Total Environ 1994;152: 179-188.

[6] Villegas Sanchez R, Martin Garcia L, Vale Parapar JF, Bello Lopez MA, Alcalde Moreno M. Characterization and Conservation of the stone used in the cathedral of Almeria (Spain). In: Riederer J, editor. Proceedings of the $8^{\text {th }}$ International Congress on Deterioration and Conservation of Stone. Germany: Berlin, 1996. vol.1, p. 89-99.

[7] Laurie AP. Stone decay and the preservation of buildings. J Soc Chem Ind 1925;27; 86-92.

[8] Klemm W, Siedel H. Sources of sulphate salt efflorescences at historical monuments - a geochemical study from Freiberg, Saxony. In: Riederer J, editor. Proceedings of the $8^{\text {th }}$ International Congress on Deterioration and Conservation of Stone. Germany: Berlin, 1996. vol.1, p. $489-495$.

[9] Gonzalez Limon T, Alvarez de Buergo Ballester M. Los revocos de cal de las fachadas de la plaza de la Corredera de Cordoba - The lime renderings from plaza de la Corredera, Cordoba. Mater Construcc 2002;52 (267): 19-30.

[10] Tulliani JM, Bertollini Cestari C. Study of the degradation causes affecting stucco sculptures from the Valentino Castle in Turín. Mater Struct 2005; 38: 425-432.

[11] Carretero MI, Galan E. Marine spray and urban pollution as the main factors of stone damage in the cathedral of Malaga (Spain). In: Riederer J, editor. Proceedings of the $8^{\text {th }}$ International Congress on Deterioration and Conservation of Stone. Germany: Berlin, 1996. vol.1, p. 311-324.

[12] Grossi CM, Murray M. Characteristics of carbonate building stones that influence the dry deposition of acidic gases. Constr Build Mater 1999; 13 (3, 1): 101-108.

[13] Benavente D, Cueto N, Martinez-Martinez J, Garcia del Cura MA, Cañaveras JC. The role of petrophysical properties of porous building rocks on salt weathering. Environ Geol 2007; 52: 197-206.

[14] Chiari G, Santarelli ML, Torraca G. Caratterizzazione delle malte antiche mediante lánalisi di campioni non fracio. Materiali e strutture: Problema di conservazione 1992; II (3): 111-137. 
[15] Bruni S, Cariati F, Fermo P, Pozzi A, Toniolo L. Characterization of ancient magnesian mortars coming from Northern Italy. Thermochim Acta 1998; 321: 161-165.

[16] Zimmerman RW, Bodvarsson G. A simple approximate solution for horizontal infiltration in a Brooks-Corey medium. Transport in Porous Media 1991; 6:195-205.

[17] Stidson RT, Hamilton-Taylor J, Tipping E. Laboratory dissolution studies of rocks from the Borrowdale Volcanic Group (English Lake District). Water Air Soil Pollut 2002; 138 (1-4): 335358.

[18] Sanjeev T, Lal Gauri K, Suhan L, Cobourn W G. Kinetic study of $\mathrm{SO}_{2}$ reaction with dolomite. Environ Sci Technol 1991; 25: 2071-2075.

[19] Al-Jibbouri S, Strege C, Ulrich J. Crystallization kinetics of epsomite influenced by pH-value and impurities. J Cryst Growth 2002; 236: 400-406.

[20] Lopez-Arce P, Doehne E, Martin W, Pinchin S. Magnesium sulfate salts and historic building materials: Experimental simulation of limestone flaking by relative humidity cycling and crystallization of salts / Sales de sulfato magnésico y materiales de edificios históricos: simulación experimental de laminaciones en calizas mediante ciclos de humedad relativa y cristalización de sales. Mater Construcc 2008; 58 (289-290). 


\section{Figure captions}

Fig. 1. Geological map and location of the Bonaval Monastery (Guadalajara, Spain). a) Monastery views from the stone outcrops facing west; b) outcrops of stone facing west.

Fig. 2. Pictures of the Monastery and collected samples. a) Monastery structure; b) map and areas of sampling; c) interior wall showing the different types of mortars analysed; d) salt samples: crust over the surface of stone and powder in the joints between blocks and under flakes of stone.

Fig. 3. Polarizing Light Microscopy pictures of sample of stone C3 from the quarry. a) Micro-fissure filled with calcite and some orange areas stained by the presence of iron oxides embedded in a dolomite matrix. b) Micro-nodule of calcite embedded in a calcareous micritic matrix with small aggregates of dolomite.

Fig. 4. ESEM analyses carried out in: a) salt crust (sample B6) and b) salt powder (sample B7), showing the presence of potassium salts, kalicinite $\left(\mathrm{KHCO}_{3}\right)$ and mercallite with needle shape $\left(\mathrm{KHSO}_{4}\right)$, together with a net of epsomite crystals; c) Dolomite crystals with signs of partial dissolution under a stone flake (sample B5).

Fig. 5. ESEM pictures from Peltier experiments of: (a) magnesium sulphate solution covering a flake of dolostone when the relative humidity was decreased from $100 \%$ down to $65 \%$ at $16^{\circ} \mathrm{C}$ (b) same flake of dolostone when the relative humidity was decreased down to $10 \% \mathrm{RH}$ at $22^{\circ} \mathrm{C}$, (c) cracking of magnesium sulphate crust, after cycling the temperature between $40^{\circ} \mathrm{C}$ and $0^{\circ} \mathrm{C}$, and the relative humidity, between $70 \%$ and $0 \%$.

Fig. 6. Phase diagram showing Relative Humidity vs. Temperature for $\mathrm{MgSO}_{4}-\mathrm{H}_{2} \mathrm{O}$ system.

Fig. 7. Water absorption by capillarity of the stones (samples B8 and B9) and mortars from the building (samples B1, B2 and B3) and stone from the quarry (sample C3).

Fig. 8. Connected porosity and pore size distribution (PSD) obtained by mercury intrusion porosimetry (MIP) of: a) stone sample from the quarry; b) and c) stones from the building; d), e) and f) mortars from the building.

Fig. 9. Sketch of the mechanism of potassium and magnesium salt formations. It is shown the combination of sulphate-bearing mortars and magnesium from the dissolution of the dolomite stone, magnesite of the plaster mortar and slate aggregates embedded in the bedding mortar with a high magnesium content. 


\section{Tables Captions}

Table 1. XRD semi-quantitative analyses from the monastery and quarry samples

Table 2. XRF analyses of the stone, mortar and salt samples.

Table 3. Connected porosity, $\mathrm{P}$, mean pore radius, $\mathrm{r}_{\mathrm{M}}$, and capillary absorption coefficient, $\mathrm{C}$, of the stones and mortar samples. 
Table 1

\begin{tabular}{|c|c|c|c|c|c|c|c|c|c|c|c|c|}
\hline$*$ & Dol & Cal & Gyp & Qz & Illit & Clin & Ms & $\mathrm{Am}$ & $\mathrm{Ab}$ & Bas & Mag & Eps \\
\hline B1-Plaster mortar & - & 76 & 9 & 1 & - & - & - & 3 & - & - & 11 & - \\
\hline B2-Bedding mortar & - & 9 & - & 56 & 11 & 10 & 10 & - & 4 & - & - & - \\
\hline B3-Core mortar & - & - & 58 & 14 & 5 & - & - & - & - & 23 & - & - \\
\hline B4-Stone scale & 100 & - & - & - & - & - & - & - & - & - & - & - \\
\hline B5-Powder under scale & 5 & - & - & - & - & - & - & - & - & - & - & 95 \\
\hline B6-Salt crust & - & - & - & - & - & - & - & 3 & - & - & - & 97 \\
\hline B7-Salt powder & - & - & - & - & - & - & - & - & - & - & - & 100 \\
\hline B8-Stone flake & 99 & - & - & 0.3 & - & - & - & 0.7 & - & - & - & - \\
\hline B9-Stone fragment & 99 & - & - & - & - & - & - & 0.3 & 1 & - & - & - \\
\hline C1-North quarry stone & 7 & 88 & - & 4 & - & - & - & 0.5 & - & - & - & - \\
\hline C2-North quarry stone & 11 & 87 & - & 2 & - & - & - & 0.6 & - & - & - & - \\
\hline C3-West quarry stone & 97 & 2.6 & - & 0.3 & - & - & - & - & - & - & - & - \\
\hline C4-West quarry stone & 98 & - & - & 1.3 & - & - & - & 1 & - & - & - & - \\
\hline
\end{tabular}


Table 2

\begin{tabular}{|c|c|c|c|c|c|c|c|c|c|c|c|c|}
\hline $\begin{array}{l}\text { Concentration } \\
(\%)\end{array}$ & B1 & B2 & B3 & B4 & B6 & B8 & B9 & $\mathrm{C} 1$ & $\mathrm{C} 2$ & C3 & $\mathrm{C} 4$ & Slate \\
\hline $\mathrm{SiO}_{2}$ & 0.63 & 44.73 & 3.53 & 4.24 & 0.07 & 1.71 & 1.51 & 4.88 & 3.45 & 5.87 & 7.03 & 65.32 \\
\hline $\mathrm{Al}_{2} \mathrm{O}_{3}$ & 0.24 & 10.55 & 1.11 & 1.54 & 0.04 & 0.51 & 0.74 & 0.85 & 0.71 & 1.78 & 1.99 & 17.13 \\
\hline $\mathrm{Fe}_{2} \mathrm{O}_{3}$ & 0.12 & 4.33 & 0.43 & 0.48 & 0.04 & 0.28 & 0.33 & 0.9 & 0.9 & 0.52 & 0.71 & 6.27 \\
\hline $\mathrm{MnO}$ & 0 & 0.06 & 0 & 0.01 & 0 & 0.01 & 0 & 0.01 & 0.01 & 0.02 & 0.02 & 0.08 \\
\hline $\mathrm{MgO}$ & 15.38 & 7.64 & 1.4 & 17.55 & 17.39 & 17.81 & 18.96 & 1.94 & 2.19 & 16.26 & 15.85 & 3.32 \\
\hline $\mathrm{CaO}$ & 30.73 & 11.18 & 26.48 & 35.7 & 3.42 & 35.78 & 36.7 & 52.11 & 51.28 & 36.52 & 33.47 & 0.57 \\
\hline $\mathrm{Na}_{2} \mathrm{O}$ & 0.8 & 0.73 & 0.24 & 0.47 & 0.02 & 0.71 & 0.32 & 0.23 & 0.23 & 0.18 & 0.14 & 1.84 \\
\hline $\mathrm{K}_{2} \mathrm{O}$ & 0.81 & 2.34 & 2.26 & 0.89 & 0.01 & 1.01 & 0.39 & 0.42 & 0.37 & 0.87 & 0.89 & 4.36 \\
\hline $\mathrm{TiO}_{2}$ & 0.01 & 0.5 & 0.04 & 0.04 & 0.01 & 0.02 & 0.02 & 0.02 & 0.01 & 0.04 & 0.07 & 0.98 \\
\hline $\mathrm{P}_{2} \mathrm{O}_{5}$ & 0.06 & 0.09 & 0.08 & 0.07 & 0.03 & 0.05 & 0.07 & 0.21 & 0.15 & 0.07 & 0.07 & 0.13 \\
\hline Lost & & & & & & & & & & & & \\
\hline (difference) & 51.21 & 17.86 & 64.42 & 39.02 & 79.01 & 42.12 & 40.95 & 38.44 & 40.7 & 37.86 & 39.76 & - \\
\hline
\end{tabular}

Concentration

(ppm)

\begin{tabular}{lrrrrrrrrrrrrr}
\hline $\mathrm{F}$ & 169 & 147 & 197 & 495 & 536.00 & 15 & 481 & 984 & 327 & 723 & 845 & - \\
$\mathrm{S}$ & 43821 & 2488 & 268561 & 9710 & 281324 & 14925 & 4562 & 736 & 818 & 1005 & 684 & - \\
$\mathrm{Cl}$ & 6338 & 2206 & 1437 & 2286 & 41 & 468 & 553 & 185 & 140 & 267 & 209 & - \\
\hline
\end{tabular}


Table 3

\begin{tabular}{|l|l|l|l|}
\hline Sample & $\mathrm{P}[\%]$ & $\mathrm{r}_{\mathrm{M}}[\mu \mathrm{m}]$ & $\mathrm{C}\left(\mathrm{kg} / \mathrm{m}^{2} \cdot \mathrm{h}^{0.5}\right)$ \\
\hline B8-Stone from building & 32.24 & 1.36 & 11.07 \\
\hline B9-Stone from building & 24.86 & 1.39 & 5.13 \\
\hline C3-Stone from quarry & 17.41 & 0.53 & 1.76 \\
\hline B1-Plaster mortar & 27.21 & 0.07 & 3.53 \\
\hline B2-Bedding mortar & 36.30 & 2.11 & 4.23 \\
\hline B3-Core mortar & 37.94 & 2.04 & 18.31 \\
\hline
\end{tabular}




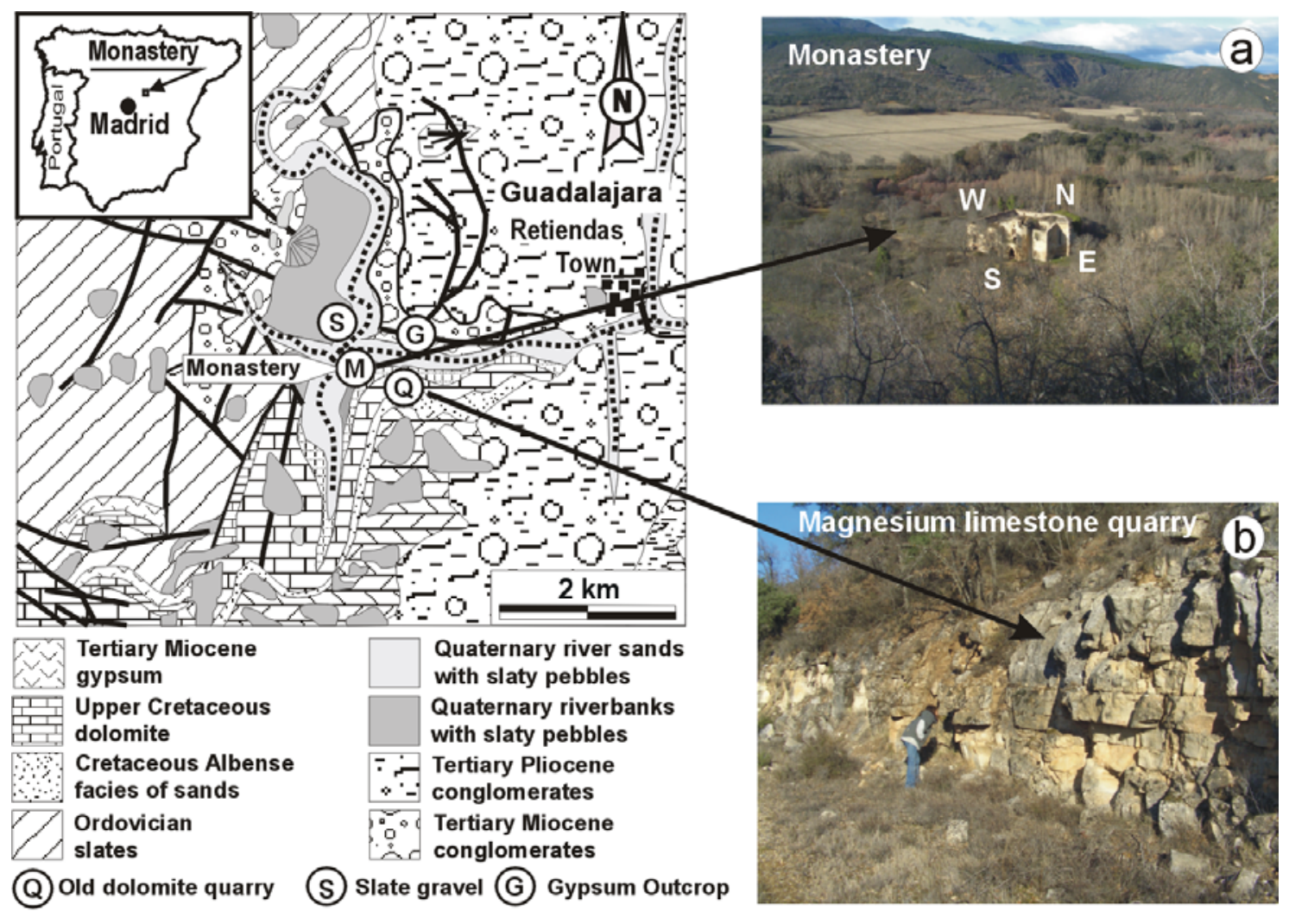

\author{
Figure 1 \\ Lopez-Arce et al.
}



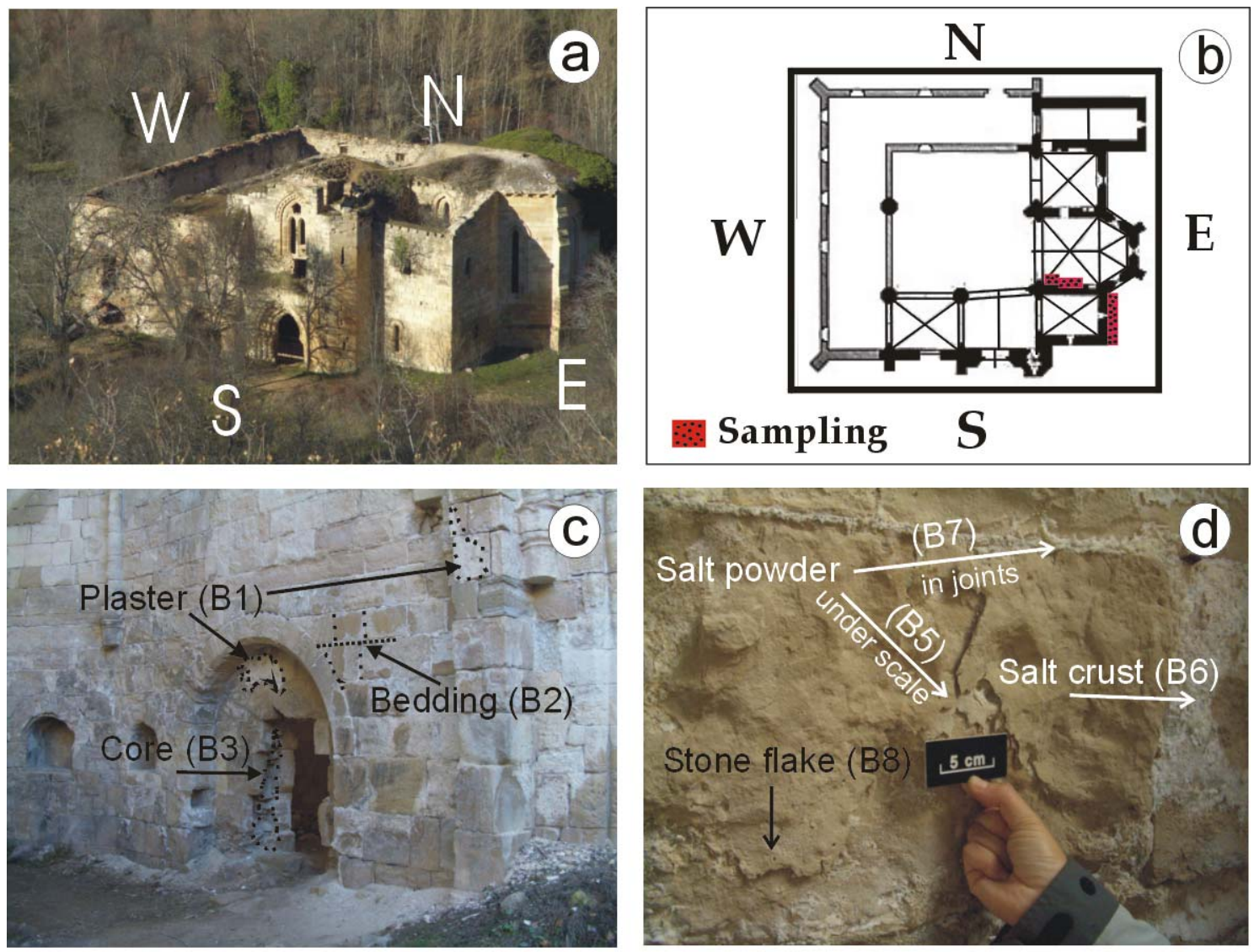

\section{Figure 2 Lopez-Arce et al.}
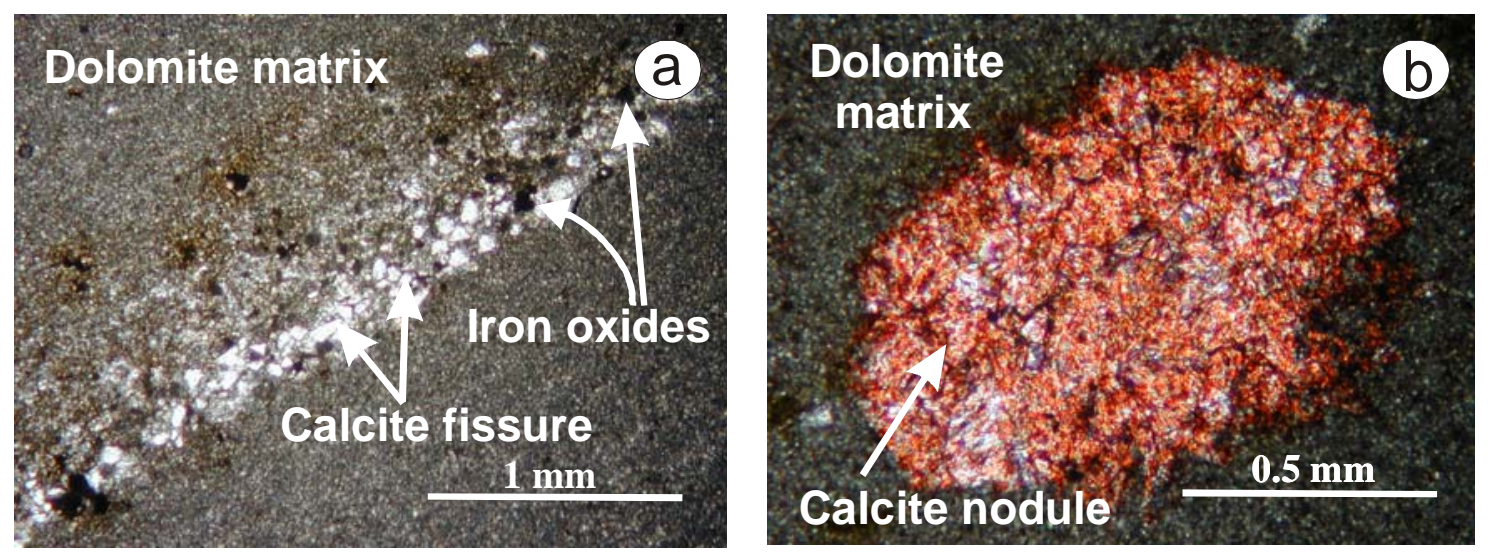

Figure 3

Lopez-Arce et al. 

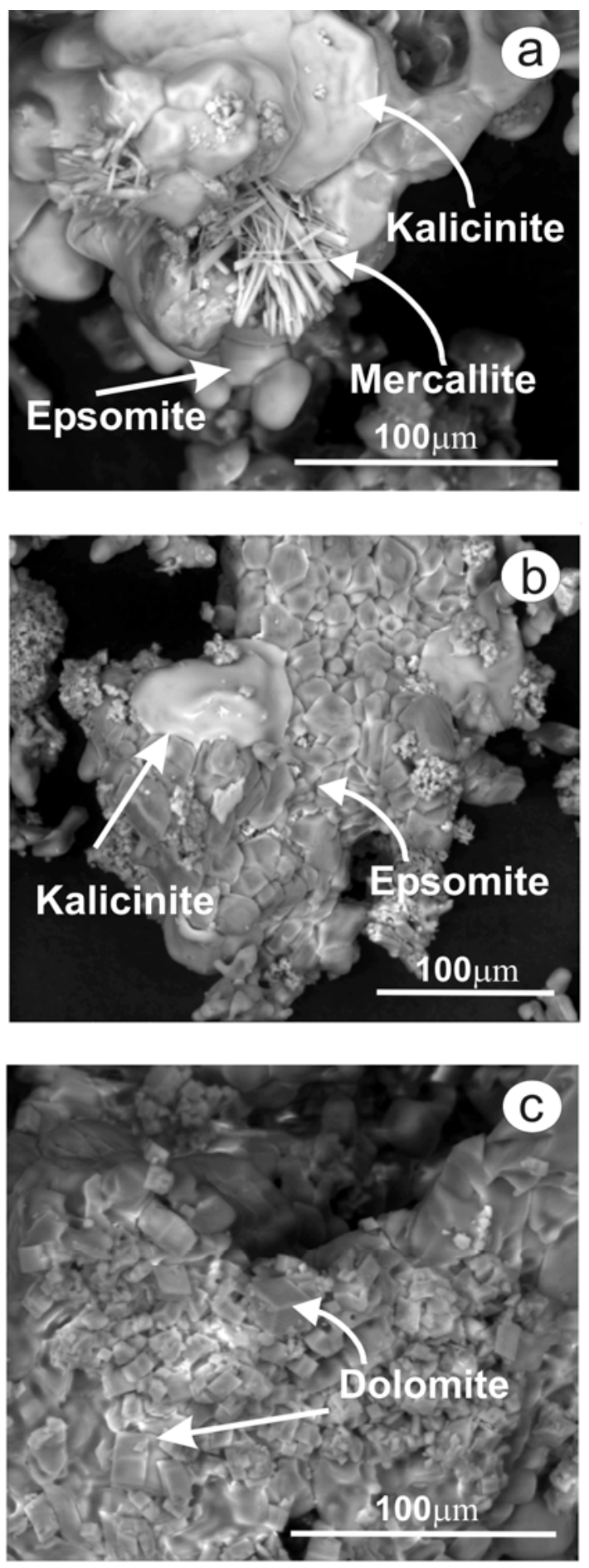

\section{Figure 4 \\ Lopez-Arce et al.}



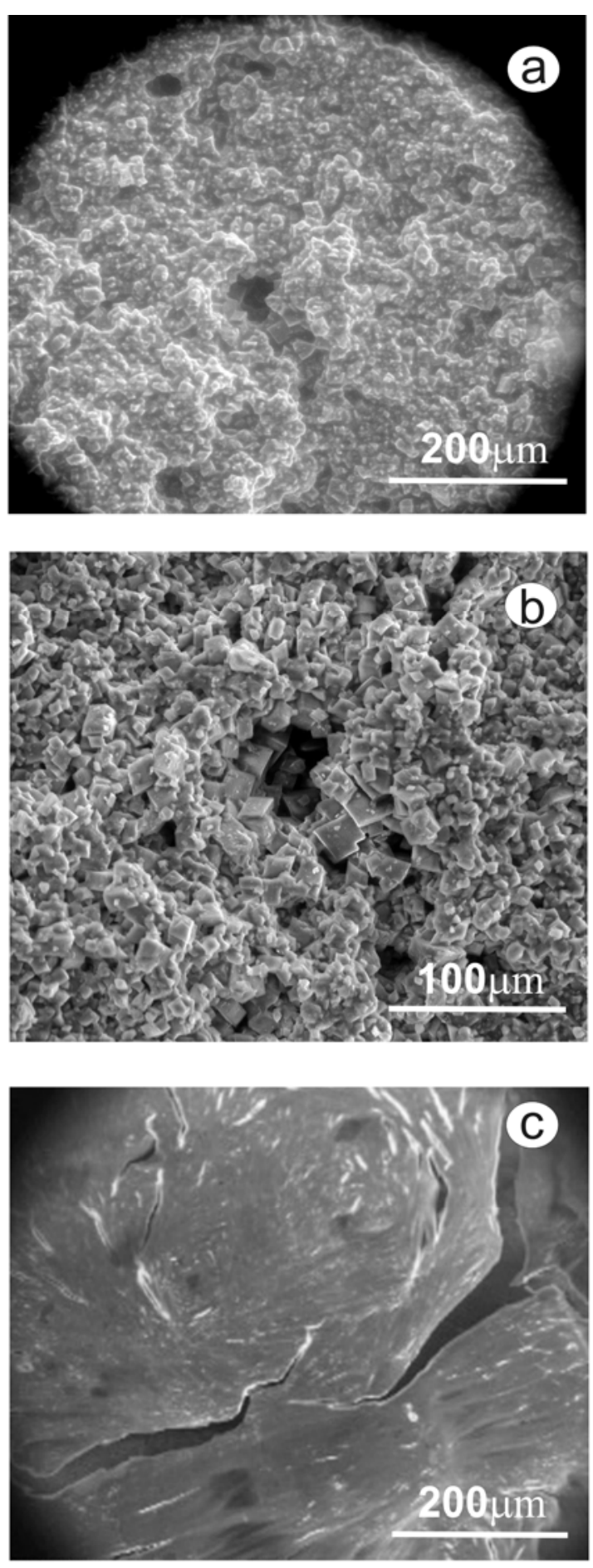

Figure 5

Lopez-Arce et al. 


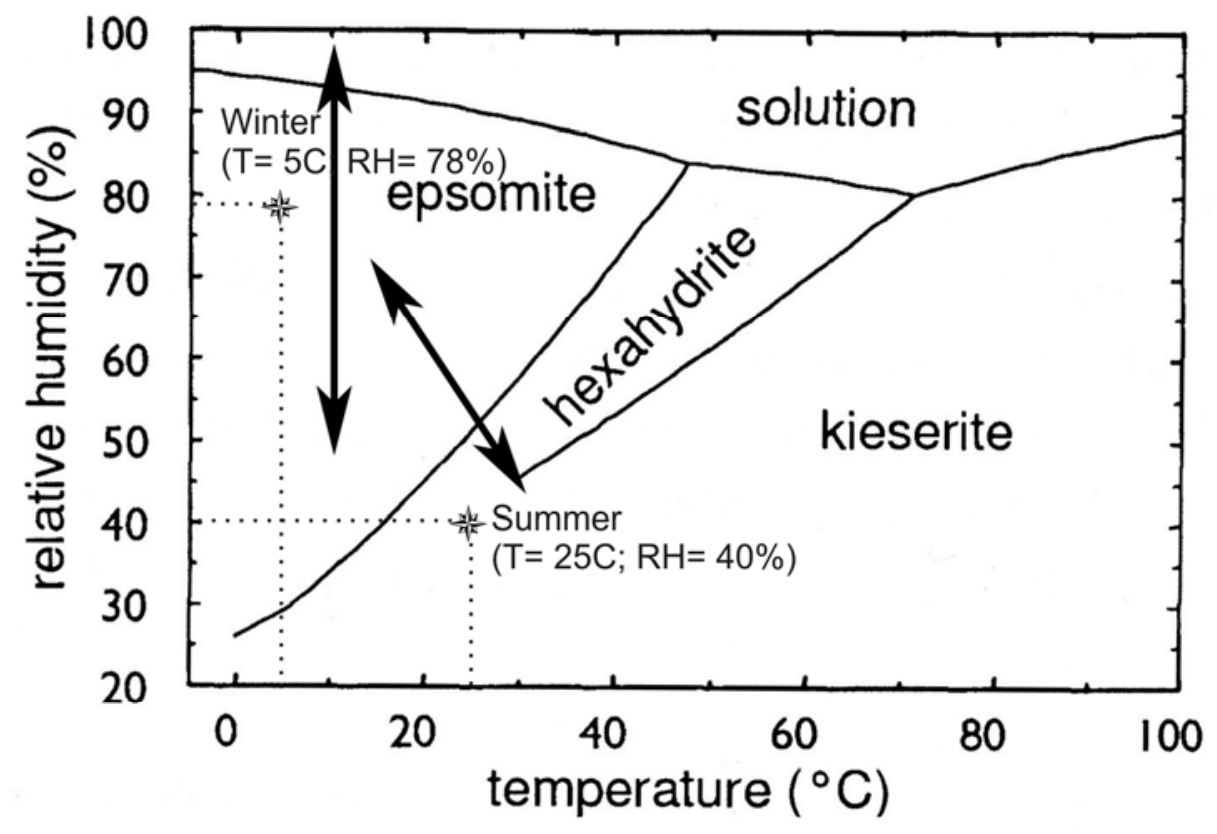

Figure 6 Lopez-Arce et al. 


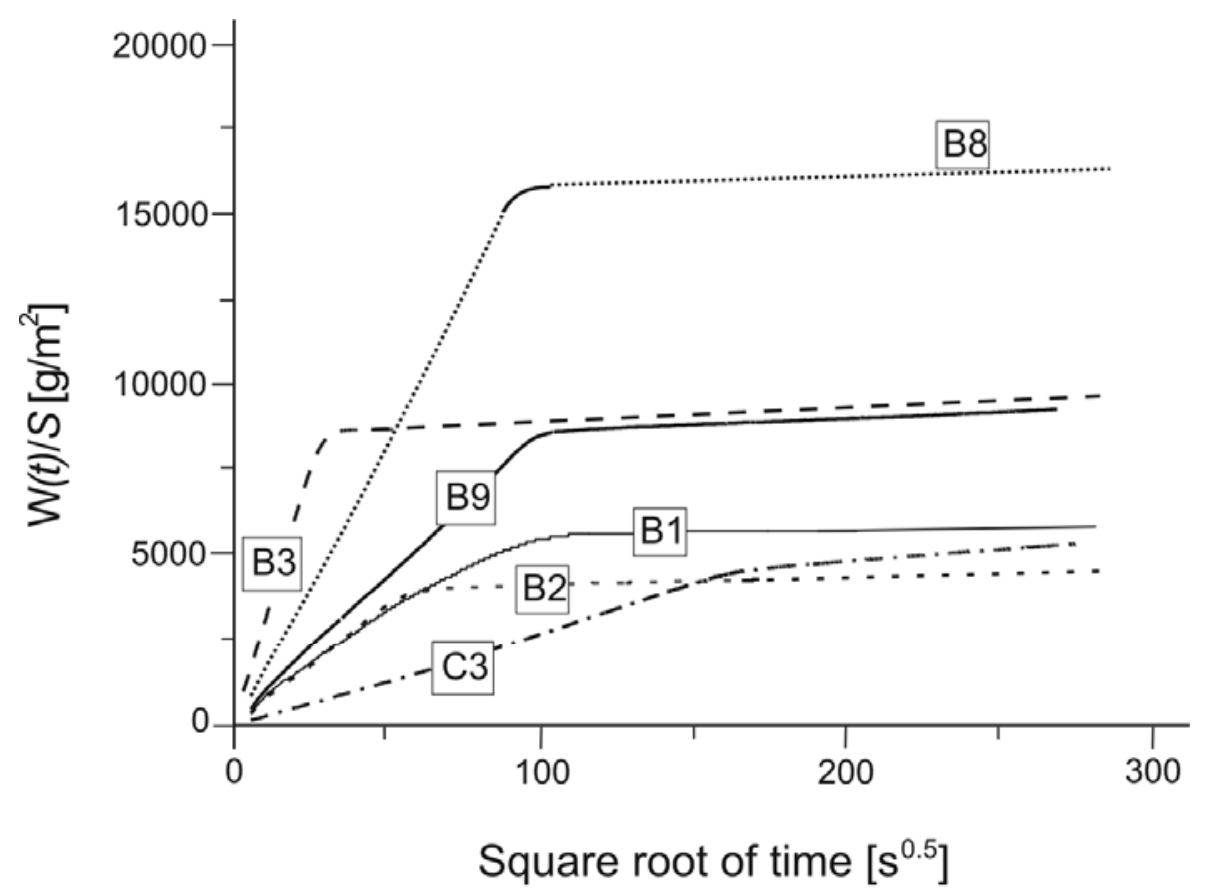

Figure 7
Lopez-Arce et al. 

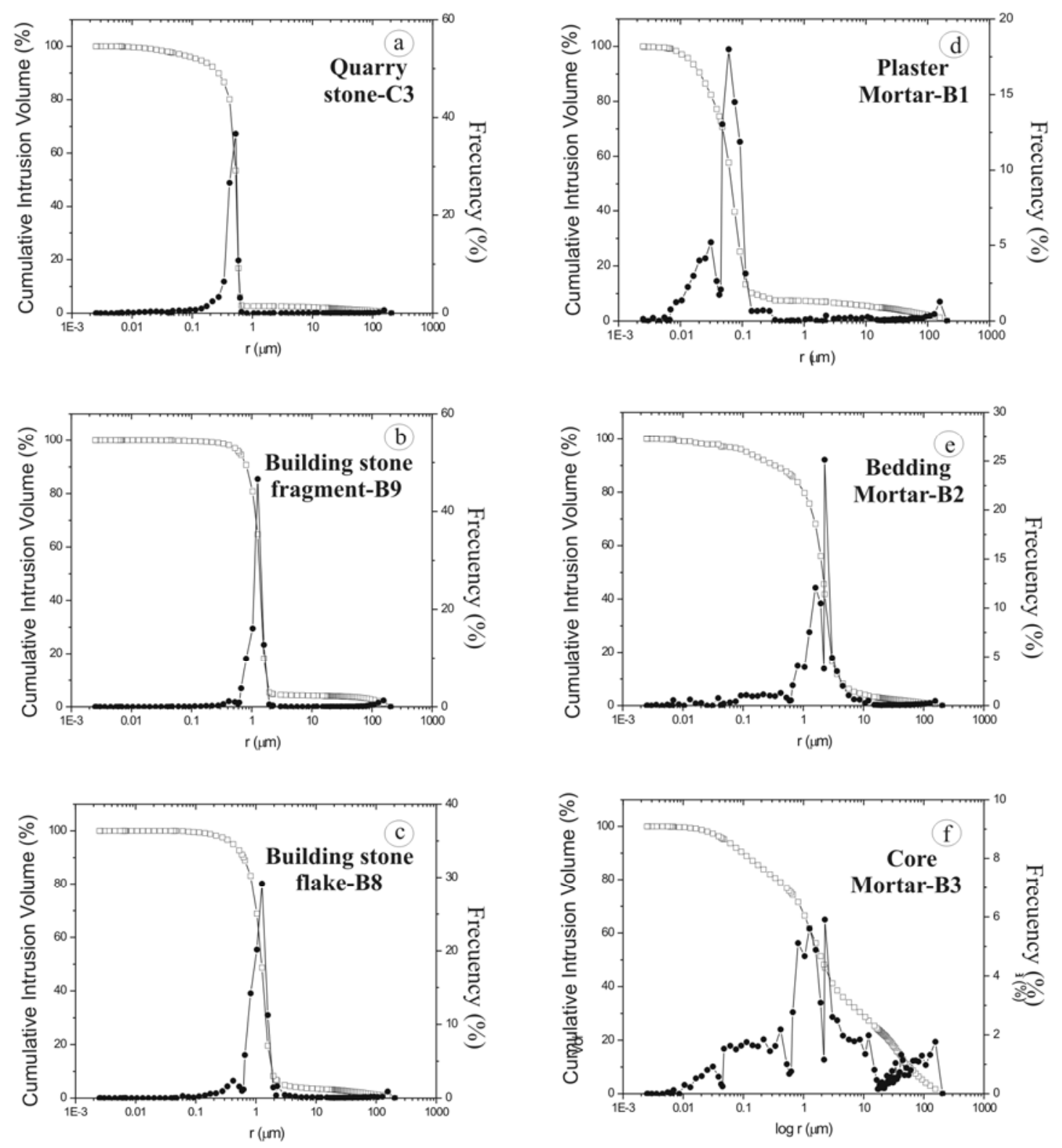

Figure 8

Lopez-Arce et al. 


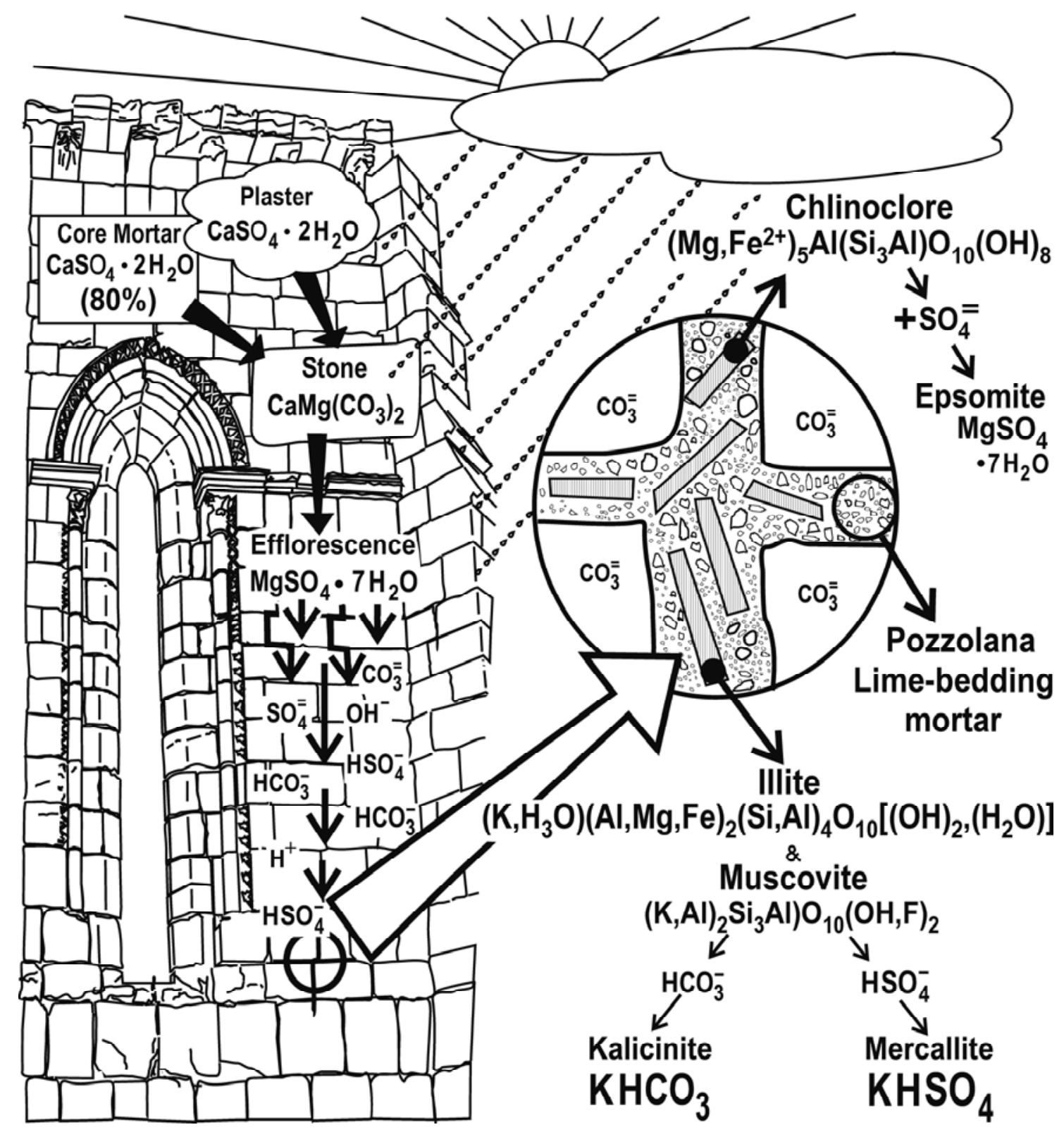

FIGURE 9 